\title{
Coal suppliers Evaluation Model Based on AHP and PROMETHEE
}

\author{
Fugui Dong \\ School of Economics and Management, \\ North China Electric Power University \\ Beijing, China \\ dfg@yeah.net
}

Abstract: The coal suppliers evaluation and selection is significant for thermal power plants to reduce the cost of power generation and enhance market competitiveness. After analyzing the limitations of the existing multiple criteria decision methods, a method for coal suppliers selection is developed by integrating analytic hierarchy process (AHP) and preference ranking organization methods for enrichment evaluations (PROMETHEE). In the process of actual evaluation, satisfaction of alternatives is the same but index value of various alternatives is different. In order to solve this problem the paper puts forward a data preprocessing method. AHP is used to analyze the structure of coal supplier selection and determine weights for evaluation criteria, and PROMETHEE is used for final raking. Finally, a numerical example is given to illustrate the efficiency of the proposed model.

Keywords: coal suppliers evaluation; AHP; PROMETHEE; Multi-Criteria analysis

\section{INTRODUCTION}

Fuel cost is the most important cost of thermal power plants because it often accounts for more than 70 percent of total cost. Well done coal suppliers evaluation and selection can greatly reduce the cost of power generation and enhance their market competitiveness.

Paper[1] made a comprehensive summary about the suppliers selection models and methods, the main ones of which are: Analytic Hierarchy Process ${ }^{[2-4]}$, ELECTRE method ${ }^{[5]}$, PROMETHEE method ${ }^{[6-9]}$, and DEA method, etc. Both AHP and DEA method have characteristics of full compensation. ELECTRE-I method constructs a weak order relations, and only gives a partial ranking of the alternatives. Although ELECTRE-II method is an improved version I, ranking all alternatives is still a herculean task. PROMETHEE method doesn't need dimensionless processing so that it avoids the information lost or distortion, and it can provide a complete ranking. However, this method can not determine the index weight, it can not alone be used for evaluation.

According to the characteristic of AHP and PROMETHEE methods, this paper proposes a model by integrating AHP and PROMETHEE to solve the problem of selection of the coal supplier. In the process of actual evaluation, satisfaction of alternatives is the same but index value of various alternatives is different. PROMETHEE method compares alternatives according to the difference between each alternative attribute and the preference index calculation is not suitable to deal with this kind of index. In order to solve this problem this paper puts forward a data preprocessing method before ranking.

\section{BUILDING COAL SUPPLIERS EVALUATION INDEX SYSTEM AND DETERMINING THE INDEX WEIGHT}

\section{A. Building Coal Suppliers Evaluation Index System}

Based on the research findings in paper[10] and [11] and combing the scene, the thesis builds an indicator system, including 4 standards and 2 performance indicators. Table 1 shows the assessment index system.

The type indicates the preference trend for each criterion, which should be 'max' for C22, C31, C41, C42, C43 and be 'min' for C21, C32. The value of coal fired quality should meet the requirements for the design of the boiler. In the process of actual evaluation, the index type of coal fired quality cannot be classified as 'max', 'min', 'middle' or 'interval'. Take calorific value as an example, satisfaction of coal is the same when the calorific value between 23 and 24 $\mathrm{KJ} / \mathrm{t}$. All the sub-criteria under $\mathrm{C} 1$ have this property.

TABLE I ASSESSMENT INDEX SYSTEM

\begin{tabular}{|l|l|}
\hline \multicolumn{1}{|c|}{ criteria } & \multicolumn{1}{c|}{ sub-criteria } \\
\hline \multirow{4}{*}{ C1 coal fired quality } & C11 calorific value \\
\cline { 2 - 2 } & $\mathrm{C} 12$ volatile matter \\
\cline { 2 - 2 } & $\mathrm{C} 13$ moisture content \\
\cline { 2 - 2 } & $\mathrm{C} 14$ ash content \\
\cline { 2 - 2 } & $\mathrm{C} 15$ sulfur content \\
\hline \multirow{2}{*}{ C2 cost element } & $\mathrm{C} 21$ unit price of standard coal \\
\cline { 2 - 2 } C3 credibility & $\mathrm{C} 22$ transport capacity \\
\hline \multirow{2}{*}{$\begin{array}{c}\text { C4 capability for } \\
\text { sevelopment }\end{array}$} & $\mathrm{C} 31$ implementation of contract \\
\cline { 2 - 2 } & $\mathrm{C} 32$ deficiency \\
\cline { 2 - 2 } & $\mathrm{C} 41$ economic benefit \\
\cline { 2 - 2 } & $\mathrm{C} 42$ Scale of Economic \\
\cline { 2 - 2 } & $\mathrm{C} 43$ Minable ability \\
\hline
\end{tabular}

B. Using Analytic Hierarchy Process (AHP) to

Determine the Index Weight

Analytical hierarchy process (AHP) is a commonly used method to determine the weight, which focuses on comparison between two indexes and the process is easily understood. The solution can be generally divided into the following steps:

(1)Construct the hierarchical structure model of the coal supplier evaluation. 
(2)Do comparison and construct judgment matrix.

(3)Level single-sort. The specific calculation is: $\mathrm{BW}=\lambda \max \mathrm{W} . \lambda \max$ is the maximum characteristic root, $\mathrm{W}$ is standardization eigenvectors corresponding to the $\lambda \max$. $\omega \mathrm{i}$, the component of $\mathrm{W}$ is the weights of the corresponding elements in a single sort.

(4)Consistency test. Computing the judgment matrix eigenvalue to measure the consistency of the matrix, usually test the consistency ratio $\mathrm{CR}$. If $\mathrm{CR}<0.1$ can determine the inconsistency of the matrix within the permissible range.

\section{USING PREFERENCE RANKING \\ ORGANIZATION METHODS FOR ENRICHMENT EVALUATIONS (PROMETHEE) TO RANK ALTERNATIVES}

PROMETHEE method compares alternatives according to the difference between each alternative attribute.

\section{A. Building Preference Function}

PROMETHEE method defines a function for each index, i.e. preference function. The function value is from 0 to 1 and the lower the value, the smaller the difference between two options. When the value is 0 there is no difference in the two options. The former option is strictly better than the latter one while the value is 1 .

The preference function for $\mathrm{xi}$ and $\mathrm{xk}$ on criterion $\mathrm{j}$ is defined as follows:

$$
P_{j}\left(x_{t}, x_{2}\right)=P\left(x_{t j}-x_{2, j}\right)=P(\mathrm{~d})
$$

$\mathrm{Pj}(\mathrm{xi}, \mathrm{xk})$ is called a generalized criterion and it reflects the intensity of the preference for xi over $x k$. The higher is $\mathrm{Pj}(\mathrm{xi}, \mathrm{xk})$, the stronger is the preference for xi over xk. Six different criteria (e.g., usual criterion, quasi criterion, level criterion) are usually taken into account [12-13] and usual criterion is adopted in this paper. Fig. 1 depicts the usual preference function $\mathrm{P}(\mathrm{d})$ which is defined as follows:

$$
\begin{aligned}
& P(d)=\left\{\begin{array}{lll}
0, & d & \leq 0 \\
1, & d>0
\end{array}\right. \\
& d=x_{t j}-x_{\mathrm{bit}}
\end{aligned}
$$

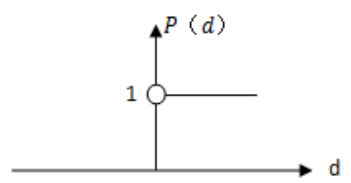

\section{FIGURE I.THE USUAL PREFERENCE FUNCTION}

\section{B. Data Preprocessing}

In the process of actual evaluation, satisfaction of alternatives is the same but index value of various alternatives is different. It is useless to do comparison according to the difference between two options without data preprocessing. Because this paper adopts the usual criterion as preference function, congruous disposal of measuring data is necessary.
(1)As for the index whose value is on the top while the option is good, let:

$$
x^{*}=\left\{\begin{array}{cc}
0, & x \geq L \\
{\left[\frac{\gamma-5}{a_{k}}\right], x<L}
\end{array}\right.
$$

Where $\mathrm{L}$ is lower bound of the most satisfied index value, [y] returns the largest integer less than or equal to $\mathrm{y}$, and ai is the interval length of the class $i$.

(2) As for the index whose value is at bottom while the option is good, let:

$$
x^{*}=\left\{\begin{array}{cc}
0, & x \leq U \\
{\left[\frac{U-x}{a_{t}}\right], x>U}
\end{array}\right.
$$

Where $U$ is upper bound of the most satisfied index value and the definition of $[y]$ and ai is consistent with earlier.

(3) As for the index whose value is close to a interval while the option is good, let:

$$
x^{*}=\left\{\begin{array}{l}
{\left[\frac{U-x}{a_{t}}\right], x>U} \\
0, L \leq x \leq u \\
{\left[\frac{x-L}{a_{j}}\right], x<L}
\end{array}\right.
$$

Because this paper adopts the usual criterion as preference function, congruous disposal of measuring data is necessary.

(4) As for the index of 'min' type, let:

$$
x^{*}=M-x
$$

$\mathrm{M}$ is the maximum of the index value.

\section{Ingoing Flow, Outgoing Flow and Net Flow}

(1) The preference index for xi over xk:

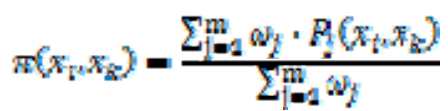

$\omega \mathrm{i}$ is the weight of the criterion $\mathrm{j}$ and $\mathrm{m}$ is the number of the criteria.

(2) Outgoing flow of the alternative xi:

$$
\Phi+\left(x_{i}\right)-\sum_{i=1} \pi\left(x_{i}, x_{k}\right)
$$

(3) Ingoing flow of the alternative xi :

$$
\Phi-\left(x_{t}\right)=\sum_{k=1}^{m} \pi\left(x_{k} x_{t}\right)
$$

(4) Net flow of the alternative xi:

$$
\Phi\left(x_{t}\right)=\Phi+\left(x_{t}\right)-\Phi-\left(x_{t}\right)
$$

Define the precedence relations from the perspective of ingoing flow and outgoing flow: 
If $\Phi+($ xi $)>\Phi+(x k)$, then xi $\mathrm{O}+\mathrm{xk}$

If $\Phi+(\mathrm{xi})=\Phi+(\mathrm{xk})$, then $\mathrm{xi} \operatorname{Ir}+\mathrm{xk}$;

If $\Phi_{-}(\mathrm{xi})<\Phi_{-}(\mathrm{xk})$, then xi O- xk;

If $\Phi$ - ( xi) $=\Phi-(x k)$, then $x i$ Ir- xk .

\section{Sorting Alternatives}

\section{(1) Using PROMETHEE-I method}

If meeting one of the following conditions, $\mathrm{xi}$ is better than $x j$, i.e. $x i \mathrm{O}(1) \mathrm{xk}$ :
1) $x i \mathrm{O}+\mathrm{xk}$ and $\mathrm{xi} O-\mathrm{xk}$
2) $x i \mathrm{O}+\mathrm{xk}$ and $x i \mathrm{Ir}-\mathrm{xk}$
3) xi O- xk and xi Ir+ xk

If $x i \mathrm{Ir}+\mathrm{xk}$ and $\mathrm{xi}$ Ir- $\mathrm{xk}$, there is no difference between $x i$ and $x k$, i.e. $x i \operatorname{Ir}(1) x k$.

If $\mathrm{xi} \mathrm{O}+\mathrm{xk}$ and $\mathrm{xk} \mathrm{O}-\mathrm{xi}$, then $\mathrm{xi}$ and $\mathrm{xk}$ cannot be compared, i.e. Xi R Xk.

According to the above precedence relation, PROMETHEE-I gives a partial ranking of the alternatives.

(2) Using PROMETHEE-II method

PROMETHEE-II provides a complete ranking with the net flows:

$$
\begin{aligned}
& \text { If } \Phi(x i)>\Phi(x k) \text {, then xi } O(2) x k \\
& \text { If } \Phi(x i)=\Phi(x k) \text {, then xi } \operatorname{Ir}(2) x k
\end{aligned}
$$

\section{IMPLEMENTATION OF THE COAL SUPPLIER SELECTION MODEL}

Taking a certain power plant as an example, there are mainly six coal suppliers to compare. The index data is listed in table2.

\section{A. Alculating the Weight of Indicators Based on AHP}

Because of the large amount of calculations, this paper adopts Super Decision software to build the hierarchical structure model of the coal supplier evaluation (see Fig.2) and calculate the weight of indicators.

TABLE II INDEX DATA OF THE ALTERNATIVES

\begin{tabular}{ccccccccccccc}
\hline & $\mathbf{C}_{11}$ & $\mathbf{C}_{12}$ & $\mathbf{C}_{13}$ & $\mathbf{C}_{14}$ & $\mathbf{C}_{15}$ & $\mathbf{C}_{21}$ & $\mathbf{C}_{22}$ & $\mathbf{C}_{31}$ & $\mathbf{C}_{32}$ & $\mathbf{C}_{41}$ & $\mathbf{C}_{42}$ & $\mathbf{C}_{43}$ \\
& $\mathrm{KJ} / \mathrm{t}$ & $\%$ & $\%$ & $\%$ & $\%$ & $\mathrm{rmb} / \mathrm{t}$ & point & point & $\%$ & point & point & year \\
\hline $\mathrm{S}_{1}$ & 23.647 & 10.99 & 7.68 & 24.19 & 1.73 & 542.17 & 10 & 9 & 0.79 & 8.8 & 8.6 & 120 \\
$\mathrm{~S}_{2}$ & 24.197 & 14.81 & 8.57 & 22.95 & 0.42 & 532.27 & 9 & 8.4 & 0.19 & 9 & 8.8 & 130 \\
$\mathrm{~S}_{3}$ & 23.962 & 8.78 & 9.29 & 21.78 & 0.97 & 488.62 & 9.5 & 8.5 & 0.71 & 8.5 & 9 & 120 \\
$\mathrm{~S}_{4}$ & 21.543 & 6.12 & 6.53 & 27.29 & 0.37 & 461.97 & 8 & 8 & 0.71 & 8 & 7.8 & 100 \\
$\mathrm{~S}_{5}$ & 21.635 & 8.7 & 9.02 & 27.77 & 0.73 & 458.65 & 7.5 & 8.8 & 0.93 & 8.3 & 7.6 & 90 \\
$\mathrm{~S}_{6}$ & 21.215 & 16.54 & 9.28 & 28.41 & 1.78 & 476.01 & 8.5 & 7 & 0.28 & 7.5 & 8 & 80 \\
\hline
\end{tabular}

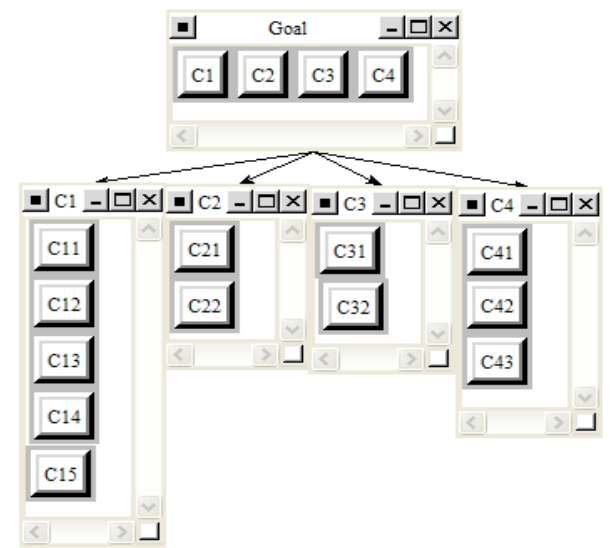

FIGURE II.

THE HIERARCHICAL STRUCTURE MODEL OF THE COAL SUPPLIER EVALUATION

Use the expert evaluation method to do comparison and construct judgment matrix in Super Decision software, take $\mathrm{C} 1$ as an example, the judgment matrix in a form of questionnaire as shown in Fig. 3.

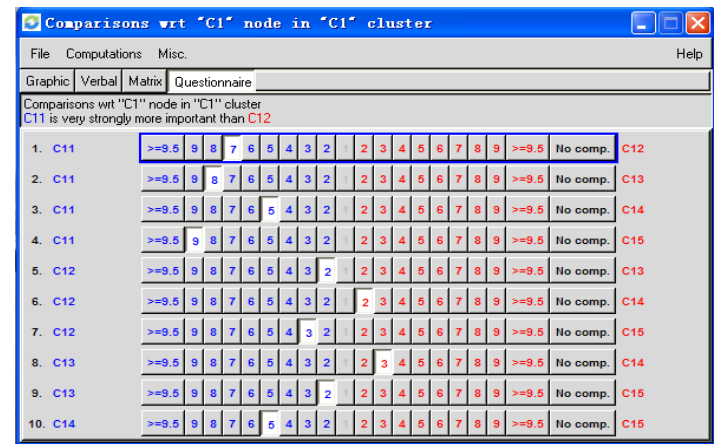

FIGURE III. THE JUDGMENT MATRIX OF CRITERIA UNDER C1

The inconsistency index is shown in Fig. 4. At 0.0287 it is less than 0.1 so it's not necessary to correct the judgments.

Finally, we can get the weight of all criteria:

$\omega=(0.152587,0.026141,0.016398,0.044515,0.010359$, $0.208333,0.041667,0.125,0.125,0.15,0.075,0.025) \mathrm{T}$

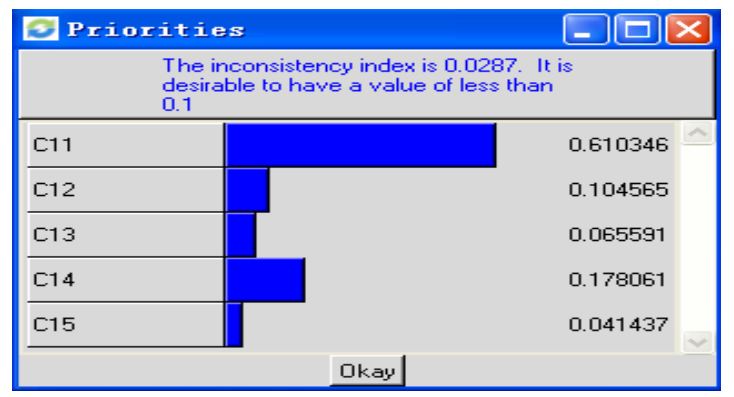

FIGURE IV.

THE WEIGHT OF CRITERIA UNDER C1 AND THE CONSISTENCY CHECK

\section{B. Ranking Alternatives}


According to the steps mentioned above to calculate the outgoing flow, ingoing flow and net flow of all alternatives and construct the precedence relations, the results is shown in table 3,4 .

TABLE III THE OUTGOING FLOW, INGOING FLOW AND NET FLOW OF ALL ALTERNATIVES

\begin{tabular}{|c|c|c|c|}
\hline & $\Phi^{+}\left(s_{i}\right)$ & $\Phi^{-}\left(s_{i}\right)$ & $\Phi\left(s_{i}\right)$ \\
\hline $\mathrm{S}_{1}$ & 2.495938 & 1.888798 & 0.60714 \\
\hline $\mathrm{S}_{2}$ & 2.289336 & 1.567001 & 0.722335 \\
\hline $\mathrm{S}_{3}$ & 2.614873 & 1.225066 & 1.389807 \\
\hline $\mathrm{S}_{4}$ & 1.486309 & 2.461702 & -0.975393 \\
\hline $\mathrm{S}_{5}$ & 1.853244 & 2.186165 & -0.332921 \\
\hline $\mathrm{S}_{6}$ & 1.580174 & 2.991142 & -1.410968 \\
\hline
\end{tabular}

TABLE IV THE PRECEDENCE RELATIONS BASED PROMETHEE-I

\begin{tabular}{|c|c|c|c|c|c|c|}
\hline & $\begin{array}{c}\text { superior } \\
\text { to } \mathrm{S}_{1}\end{array}$ & $\begin{array}{c}\text { superior } \\
\text { to } \mathrm{S}_{2}\end{array}$ & $\begin{array}{c}\text { superior } \\
\text { to } \mathrm{S}_{3}\end{array}$ & $\begin{array}{c}\text { superior to } \\
\mathrm{S}_{4}\end{array}$ & $\begin{array}{c}\text { superior } \\
\text { to } \mathrm{S}_{5}\end{array}$ & $\begin{array}{c}\text { superior } \\
\text { to } \mathrm{S}_{6}\end{array}$ \\
\hline $\mathrm{S}_{1}$ & & $\mathrm{O}^{+}$ & & $\mathrm{O}^{+} / \mathrm{O}^{-}$ & $\mathrm{O}^{+} / \mathrm{O}^{-}$ & $\mathrm{O}^{+} / \mathrm{O}^{-}$ \\
\hline $\mathrm{S}_{2}$ & $\mathrm{O}^{-}$ & & & $\mathrm{O}^{+} / \mathrm{O}^{-}$ & $\mathrm{O}^{+} / \mathrm{O}^{-}$ & $\mathrm{O}^{+} / \mathrm{O}^{-}$ \\
\hline $\mathrm{S}_{3}$ & $\mathrm{O}^{+} / \mathrm{O}^{-}$ & $\mathrm{O}^{+} / \mathrm{O}^{-}$ & & $\mathrm{O}^{+} / \mathrm{O}^{-}$ & $\mathrm{O}^{+} / \mathrm{O}^{-}$ & $\mathrm{O}^{+} / \mathrm{O}^{-}$ \\
\hline $\mathrm{S}_{4}$ & & & & & & $\mathrm{O}^{-}$ \\
\hline $\mathrm{S}_{5}$ & & & & $\mathrm{O}^{+} / \mathrm{O}^{-}$ & & $\mathrm{O}^{+} / \mathrm{O}^{-}$ \\
\hline $\mathrm{S}_{6}$ & & & & $\mathrm{O}^{+}$ & & \\
\hline
\end{tabular}

From table 3 and 4 we can conclude the precedence relations based PROMETHEE-I, PROMETHEE-II:

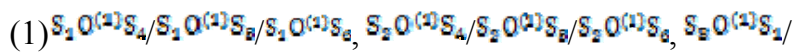

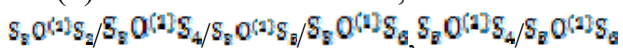

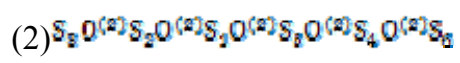

Then construct the precedence relation directed graph as shown in Fig. 5.<smiles>[Hg]C1CCCC1</smiles>

(i)

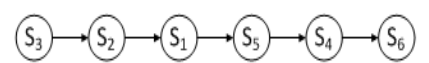

(ii)
FIGURE V.

THE PRECEDENCE RELATION DIRECTED GRAPH

Graph (i) is based on PROMETHEE. We can see that supplier S3 is best, S1 and S2 is better, then S5, and the last two are S4 and S6. It is also proved that PROMETHEE-I gives a partial ranking of the alternatives.

From graph (ii) we can see a complete ranking, i.e. $S_{2} \times S_{2}>S_{1} \times S_{2}>S_{4} \times S_{6}$

In summary, coal supplier S3 is the best choice which is much better the other suppliers, and S2 and S1 are next choice.

\section{CONCLUSION}

In order to help coal-fired power plants solve the problem of coal supplier selection, this paper provides an evaluation model based on AHP and PROMETHEE. This model uses AHP to ascertain the weight of each index according to practical importance so that it can simplify complex problems. In the process of actual evaluation, satisfaction of alternatives is the same but index value of various alternatives is different. In order to solve this problem a data preprocessing method is used. Then PROMETHEE method is adopted to rank alternatives and overcomes the weakness of AHP which has characteristics of full compensation. Finally, a numerical example is given to illustrate the efficiency of the proposed model.

\section{ACKNOWLEDGMENTS}

This paper is supported by "Education reform project of North China Electric Power University (2014JG37)" and "the Fundamental Research Funds for the Central Universities"(12MS71).

\section{REFERENCES}

[1] LIU Xiao,LI Hai-yue,WANG Cheng-en,CHU Cheng-bin. A Survey of Supplier Selection Models and Approaches. Chinese Journal of Management Science, 2004,12(1):139-148.

[2] Ali Kokangula,Zeynep Susuz. Integrated analytical hierarch process and mathematical programming to suppliers election problem with quantity discount. Applied Mathematical Modelling,2009, 33(3):1417-1429.

[3] R.Mohammad Ebrahima,J.Razmia,H.Haleh. Scatter search algorithm for supplier selection and order lot sizing under multiple price discount environment. Advances in Engineering Software, 2009, 40(9):766-776.

[4] Fereshteh Mafakheria,Michele Bretonb,Ahmed Ghoniemc. Supplier selection order allocation: A two-stage multiple criteria dynamic programming approach. International Journal of Production Economics, 2011,132(1):52-57.

[5] CHENG Yan,WANG Ming-chun,FENG Jia-yi. Outsourcer selection based on noun-type attribute weights of ELECTRE-I. Journal of Tianji University of Technology and Education, 2009, 19(4):37-39.

[6] Riccardo Dulmin,aleria Mininno. Supplier selection using a multi-criteria decision aid method.Journal of Purchasing and Supply Management,2003,9(4):177-187.

[7] Ceyhun Araz,Irem Ozkarahan. Supplier evaluation and management system for strategic sourcing based on a new multi criteria sorting procedure. International Journal of Production Economics,2007, 106(2):585-606.

[8] Ceyhun Araz,Pinar Mizrak Ozfirat,Irem Ozkarahan. An integrated multi criteria decision-making methodology for outsourcing management. Computers \& Operations Research, 2007, 34(12): 3738-3756.

[9] WANG Jian-jun, WEI Cai-min, YANG De-li. A decision method for vendor selection based on AHP/PROMETHEE/GAIA. Journal of Dalian University of Technology, 2006, 46(6): 926-931.

[10] Wang wei. Fuel Strategic Purchasing Management of Liaocheng Power Plant. Beijing: North China Electric Power University,2008.

[11] Wei jie. Optimization Management of Fengcheng Power Plant Fuel Suppliers. Beijing: North China Electric Power University, 2007.

[12] E. Ocelíková,D. Klimešová. Using PROMETHEE method for the Ranking of Multidimensional Data. IEEE International Symposium on Applied Machine Intelligence and Informatics, 2010.

[13] Yi-Chung Hu,Chiung-Jung Chen. A PROMETHEE-based classification method using concordance and discordance relations and its application to bankruptcy prediction. Information Sciences,2011,181(22):4959-4968. 